Article

\title{
Social Psychological Theories and Sustainable Second Language Learning: A Model Comparison Approach
}

\author{
Kyung Ja Kim ${ }^{1}$ and Tae-Il Pae ${ }^{2, *}$ \\ 1 Department of English Education, College of Education, Chosun University, Gwangju 61452, Korea; \\ kyung9@chosun.ac.kr \\ 2 Department of English Language Education, School of Education, Yeungnam University, \\ Gyeongsan 38541, Korea \\ * Correspondence: paet@ynu.ac.kr; Tel.: 82-2-961-0863
}

Received: 9 December 2018; Accepted: 19 December 2018; Published: 20 December 2018

check for updates

\begin{abstract}
The purposes of the present study are two-fold: (1) To examine whether social psychological variables, such as attitude and subjective norm, can predict South Korean English as a foreign language high school students' intention to learn English, and (2) to identify the best social psychological model for sustainable second language learning in the context of South Korean English as a foreign language (EFL) learning. A total of 614 South Korean high school learners of English participated in the present study. Data collected from a survey questionnaire were analyzed using a structural equation modeling procedure. Results of the present study indicate that South Korean high school students' attitudes toward learning English and subjective norms made a significant and independent contribution to the variance in their intention to study English. Among the three competing social psychological models examined in the current study, the theory of Planned Behavior and an expanded model of Gardner's Socio-educational Model proved to be the most effective in terms of the strength of path coefficients and explanatory power. Theoretical and pedagogical implications are provided.
\end{abstract}

Keywords: sustainable development; social psychology; second language acquisition; theory of reasoned action; theory of planned behavior; socioeducational model

\section{Introduction}

Sustainability and sustainable development are critical for well-being and quality of life. To promote sustainability around the world, the United Nations proposed 17 goals for sustainable development across diverse areas [1]. As seen by the fact that a majority of the sustainable development goals proposed by the United Nations pertain to economic and ecological domains, it is evident that the issues of sustainability and sustainable development in psychological and sociocultural dimensions both at the level of individuals and at the society are underrepresented in the literature of sustainability [2]. In this regard, it is notable that the concept of psychology of sustainability and sustainable development bridges this gap by adding a psychological framework of research to probe the issues related with sustainability for individuals in the environments [3,4].

Language learning is an important avenue of investigation in the psychological and sociocultural understanding of sustainable development, since sustainable development would be impossible without effective communication among people, and language plays a crucial role in mediating the relationships between people, society, and the environment. For these reasons, the process of learning a language has received intense attention from educators and psychologists. Moreover, language is the main medium of instruction for a quality education at all levels across diverse subject areas, which is recognized by the United Nations and the UNESCO as the foundation for creating sustainable 
development $[1,5]$. In fact, being able to communicate with other people using a language allows access to education, which helps people to come up with innovative solutions to the world's problems.

As the world is globalized and interdependent, learning a second language (L2) is gaining more importance, because the ability to communicate using an L2 helps to enrich the quality of one's life by understanding people with culturally different thoughts and behavioral patterns. Therefore, learning an L2 provides an opportunity to intensify the bonds between people from around the world and supports global citizenship and sustainable development. Given the potentials of L2 learning for sustainability and sustainable development, the present study intends to examine the utility of social psychological theories of L2 learning in explaining the psychological and sociocultural basis of learning English as a foreign language (EFL) for Korean L2 learners.

\subsection{Study Significance}

With the increasing use of English across personal, academic, and business sectors worldwide, English as a second or foreign language has gained more theoretical and practical importance. As a result, the etiology of learner differences in the acquisition of English has been a key topic in the field of L2 learning and teaching, and a number of attempts have been made to predict determinants of successful L2 acquisition across linguistic, cognitive, and affective domains. Among the many predictors, behavioral intention has received intense attention from social psychologists. Intention-based approaches primarily focus on behavioral intention to predict human behaviors and explore diverse factors that directly or indirectly influence behavioral intention. This framework of understanding human behavior has proved useful in explaining a wide range of human behaviors. The conceptualization of human behaviors as a function of behavioral intention is derived from social psychological theories. For instance, the Theory of Reasoned Action (TRA) proposed by Fishbein and Ajzen [6] and its extension, the Theory of Planned Behavior (TPB) [7] commonly emphasize the importance of social psychological variables, such as attitudes toward the behavior and subjective norm (i.e., learners' perceptions of significant others' opinions), as antecedents of behavioral intention. These social psychological models have been successfully utilized in the study of diverse human behaviors, such as voting, weight loss, consumer and tourist behavior, and educational decisions [8].

In the field of L2 learning and teaching, however, TRA and TPB have rarely been utilized despite their potential to facilitate understanding about the L2 acquisition process from a social psychological perspective [9]. Instead, a social psychological theory of L2 acquisition based on attitudes and motivation has been the focus of a number of empirical studies [10]. The present study empirically explores the utility of different social psychological theories as a model for explaining EFL learning in the South Korean context. The study purposes are two-fold: To examine whether social psychological variables, such as attitude and subjective norm, can predict South Korean EFL high school students' intention to learn English, and to identify the best social psychological model of L2 learning in the context of South Korean EFL learning.

\subsection{Social Psychological Context of EFL Learning in South Korea}

As noted by Pae [11], EFL learning and teaching in South Korea have traditionally been dominated by a structural syllabus, which prioritizes deductive rule explanations without meaningful communicative interactions between the teacher and the learners [12,13]. As a result, English classrooms have typically been characterized by grammar teaching and translation. However, after the recent educational reform, which implemented a communicative language teaching (CLT) framework, EFL teaching and learning in South Korea now tend to emphasize communicative interactions, and accordingly, CLT has been a guiding principle in curriculum design, materials development, and teaching and learning methods $[14,15]$.

From a social psychological perspective, English has been considered a key for success in South Korea, and competence in English opens up better opportunities in university admission, job seeking, and business transactions. Hence, South Korean learners of English tend to show pragmatic or 
extrinsic motivation, rather than intrinsic motivation [16-18]. More recently, increasing communicative demands using English as a medium of communication around the world have pushed many South Korean people to pay more attention to the acquisition of English communicative competence, via methods such as establishing a so-called "Wild Geese Family" $[15,19,20]$. This term describes South Korean families who choose to live in separate countries to provide better educational opportunities for their children to acquire English competence, by schooling their children in English-speaking countries where the mother and children live while the fathers remain in South Korea to work [21]. This educational phenomenon suggests that English learning in South Korea is more than a simply educational variable. Rather, it has a greater degree of social psychological implications, which positions itself in the broader context of language and social psychology. In this sense, English learning in South Korea has become a socially defined construct vulnerable to social pressure.

The cultural composition of South Korean society is another factor that requires a social psychological view, such as TRA and TPB, in understanding EFL learning in South Korea. As suggested by previous studies [12,22], far eastern countries, including South Korea and China, are a society based on collectivism so that citizens tend to be submissive to social expectations, and their behaviors are greatly influenced by external opinions and social acceptance. They worry about losing face by behaving counter to the expectations of significant others and they are eager to give a favorable impression. This cultural orientation indicates that perceived opinion of significant others in reference to the behavior in question, or subjective norm, which reflects individual's perceptions of the social pressures made onto him or her [8], is a critical element in understanding the social psychological structure underlying South Korean learners' EFL learning. Therefore, it is evident that social psychology is a theoretical framework relevant to the South Korean context of EFL learning and teaching. Nevertheless, very few attempts have been made to utilize social psychological theories in explaining the social and psychological basis of EFL learning in South Korea. The following section briefly introduces the social psychological theories targeted in the present study and reviews relevant literature.

\section{Targeted Theories and Review of Relevant Literature}

The present study targets four theories which have potential implications for the understanding of L2 acquisition from a social psychological perspective: TRA, TPB, Gardner's socioeducation model (SM), and Clément's theory of linguistic self-confidence.

\subsection{TRA: Model 1}

Based on the assumption that humans are highly motivated and eager to utilize information from a variety of sources to reach a rational decision to perform a certain behavior, Ajzen and Fishbein [8] proposed a model of social behavior to systematically account for the influences of social psychological factors on their behavior. TRA, originally resulting from an attitude-based model of social behavior (e.g., expectancy-value model), is a theoretical attempt to consider the discrepancies between attitude and behavior. As briefly mentioned in the introduction, a key element in TRA is behavioral intention, which represents a person's motivational drive or a conscious plan to perform a behavior [7]. Based on the idea that the shorter the temporal distance between intention and the actual behavior, the stronger the correlation between intention and the actual behavior [23], Fishbein and Ajzen [6] argued that accurately measured intention is the best predictor of behavior. Thus, according to TRA, intention causes behavior, given an opportunity to act. The significant relationships between behavioral intention and actual behavior have been confirmed through empirical studies [24].

TRA further posits that behavioral intention is a function of attitude toward the behavior and the person's subjective norm. The first antecedent, attitude toward the behavior, reflects the influence of the expectancy-value model, whereas the second antecedent is a new addition unique to TRA. According to Ajzen and Fishbein [8], attitude refers to "a given person's general evaluation or overall feeling of favorableness or unfavorableness toward the behavior in question" ([8], p. 55). On the other 
hand, subjective norm pertains to the perceptions that significant others think an individual should perform the behaviors in question. Significant others include those persons important to the individual, such as parents, siblings, friends, teachers, and relatives. Thus, subjective norm is reflective of the individual's perceptions of the social pressures made onto him or her. Previous empirical studies based on TRA indicate that attitudes and subjective norm made a significant and independent contribution to various behavioral intentions, as noted by Ajzen and Fishbein [8] and Ajzen [25].

In the field of L2 learning, few studies have tested the validity of TRA. For instance, Livesey, Crawley, and Blanco [26] investigated the relationships between attitudes, subjective norm, and behavioral intention in the Chinese EFL context. They measured the participants' attitudes, subjective norm, and behavioral intention in relation to the degree of engagement in EFL learning activities across seven categories. The results of multiple regression analyses demonstrated that students' attitudes toward engagement in EFL learning activities across seven specific categories of L2 learning behaviors and subjective norm explained significant proportions of the variances in students' intention to engage in these activities, with attitudes explaining more of the variances than subjective norm. These results clearly evidenced the utility of TRA as a theoretical framework for relating affective variables to behavioral intention in the EFL setting.

Most recently, Pae [27] examined the effects of social psychological variables on EFL achievement using two proficiency groups of 268 Korean high school EFL students. The social psychological variables targeted in this study included students' attitudes toward EFL learning and subjective norm, and students' EFL achievement was assessed by the Korean national standardized test of English accomplishment. Based on a structural equation modeling (SEM) technique, Pae [27] showed that overall attitudes, subjective norm, and linguistic self-confidence made a significant and independent contribution to students' EFL achievement, thereby lending support to the validity of TRA in the Korean EFL context. By proficiency level, however, no significant relationship was found between subjective norm and English accomplishment for the students in a lower proficiency group. This finding suggests that perceptions of significant referents' opinion did not significantly influence the level of English accomplishment of the students with lower English proficiency, unlike their counterparts with higher English proficiency.

\subsection{TPB: Model 2}

TPB is an extended version of TRA with the added element of perceived behavioral control, which refers to an individual's perceptions about his or her ability to perform the behavior in question. This nonvolitional control factor is a measure of how competently a person can execute the actions required under specific situations [25]. Perceived behavioral control reflects an individual's perceptions of the situational factors that may facilitate or impede the performance of the behavior $[7,25]$. The need for behavioral control is justified, given that TRA is based on the assumption that behaviors are voluntary and under volitional control. This suggests that without taking behavioral control into consideration, TRA may not be applicable to the behaviors with nonvolitional control, hence compromising the predictive power of TRA [28]. Therefore, attitudes, subjective norm, and behavioral control act as the core variables of TPB, and this triadic framework as an antecedent of behavioral intention is an effort to enhance the utility of TRA to better deal with a variety of social behaviors $[7,25]$.

Similar to the case with TRA, very few empirical studies have been conducted utilizing TPB as the theoretical basis in relation to L2 learning and teaching [29,30]. Zhong [30], for instance, successfully applied TPB in understanding Chinese learners' willingness to communicate (WTC) in English in the context of a New Zealand ESL classroom. Using a qualitative research design, Zhong investigated the factors influencing five Chinese ESL learners' L2 WTC in two types of class (i.e., traditional teacher-led vs. collaborative setting) based on the data collected from in-depth and stimulated recall interviews, classroom observations, and learning logs. The results revealed that Chinese ESL learners' WTC varied as a function of the class type, and these variations were analyzed according to TPB. Underwood [29] extended the scope of TPB by studying the curriculum impact in the Japanese EFL 
context. Specifically, using a qualitative method, Underwood explored the beliefs of six Japanese senior high school teachers in response to the current reform of Japanese national curriculum for English in terms of the integration of grammar with CLT, and the Japanese high school teachers' beliefs were analyzed across three domains of TPB (i.e., behavioral beliefs, normative beliefs, and control beliefs). The findings suggest that Japanese senior teachers held unfavorable attitudes and perceptions about the curriculum reform, and these negative attitudes were attributed to the misconceptions regarding high-stakes exams and insufficient resources, such as time and training.

\subsection{SM \& Clément's Linguistic Self-confidence: Model 3}

The socioeducational model (SM) of L2 acquisition proposed by Gardner is derived from social psychological foundations in that it focuses on a complex of attitudinal, goal-directed, and motivational variables. According to the model, L2 achievement is a function of motivation and a set of attitudinal variables. Motivation is the core element of Gardner's model, and it operationally comprises three components (motivational intensity, desire to learn an L2, and attitudes toward learning an L2). This model has successfully been applied to explain L2 acquisition for diverse learners [10,31], including Korean EFL learners [11].

Linguistic self-confidence in the context of language and social psychology is a concept originally proposed by Clément. Clément defines self-confidence as the self-perceptions of one's L2 competence and a lack of L2 anxiety [32,33]. Over the past years, Clément and colleagues have examined the complex relationships between social contextual factors, attitudinal and motivational variables, self-confidence, and L2 acquisition. The results of these examinations generally indicated that positive attitudes toward an L2 would bring about more contacts between members in different language communities. These enhanced contacts in turn result in a powerful mediating motivational process identified as self-confidence, and in such a context, self-confidence acts as a strong determinant of future desire of intercultural communication [32-35]. Previous empirical studies utilizing EFL samples also evidenced that the linguistic self-confidence is a significant predictor of English achievement [11,27].

\subsection{Model Comparison and Research Questions}

To find the best social psychological model in the South Korean EFL context, the three competing SEM models (i.e., TRA, TPB, and SM Expanded) were developed, and the relative utility of each of these three models was quantitatively compared. Specifically, Model 1 was composed of two latent exogenous variables (i.e., attitudes and subjective norm) and one latent endogenous variable (i.e., behavioral intention), as delineated by the TRA. Figure 1 in the Results section schematically presents SEM model 1. Model 2 reflects TPB, and this model added one more latent exogenous variable (i.e., perceived behavioral control) to Model 1, as presented in Figure 2. The utility of the linguistic self-confidence and the motivation construct as suggested by Gardner and Clément in explaining South Korean students' EFL learning was examined through Model 3 (SM Expanded). Model 3 is a model combining the motivation part of the SM with Clément's linguistic self-confidence, and accordingly, Model 3 consisted of four latent exogenous variables (i.e., attitude, motivational intensity, desire to learn English, and linguistic self-confidence) and one latent endogenous variable (i.e., behavioral intention), as shown in Figure 3 in the Results section. Linguistic self-confidence was studied in combination with the SM, since there is a close theoretical link between Clément's linguistic self-confidence and Gardner's SM in that both of them commonly emphasized the importance of social contextual variables in L2 learning. 


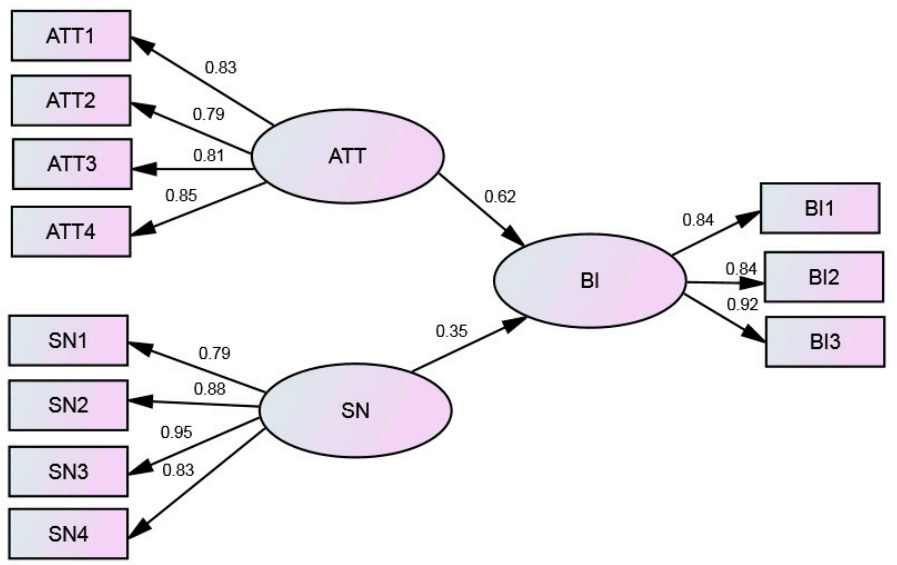

Figure 1. Schematic Presentation of Model 1. Note. ATT = Attitude; SN = Subjective Norm; $\mathrm{BI}=$ Behavioral Control.

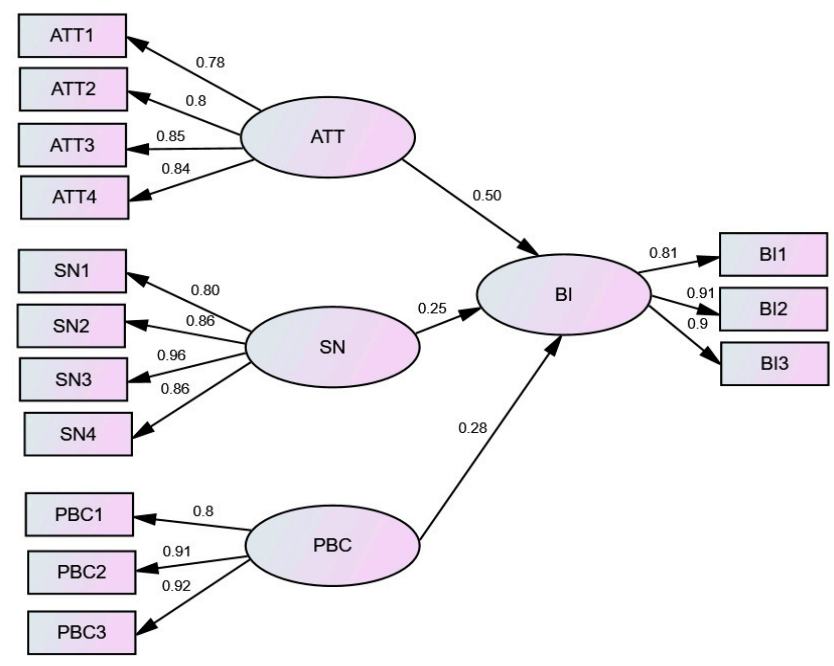

Figure 2. Schematic Presentation of Model 2. Note. ATT = Attitude; SN = Subjective Norm; $\mathrm{PBC}=$ Perceived Behavioral Control; $\mathrm{BI}=$ Behavioral Control.

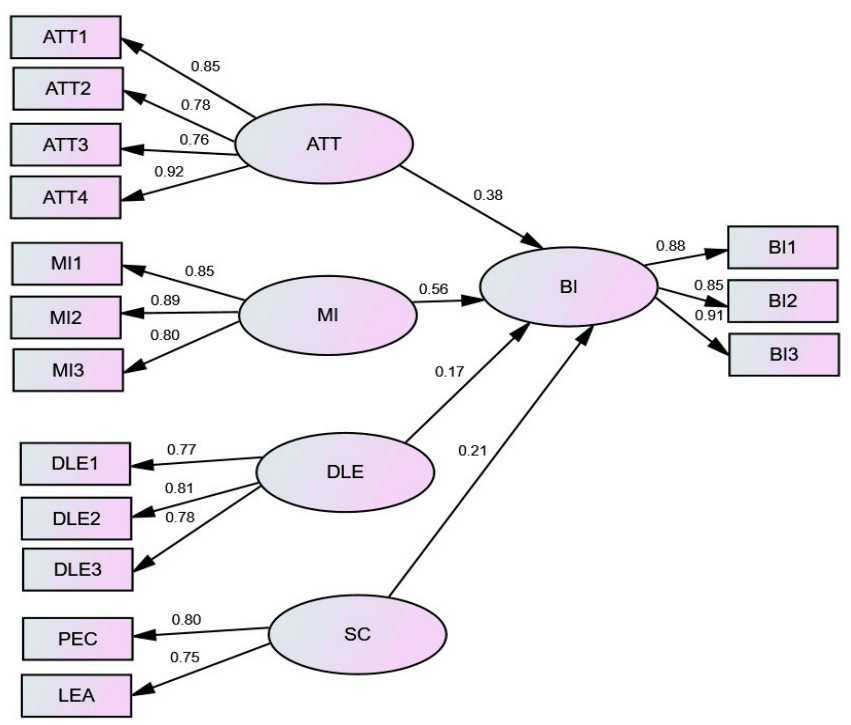

Figure 3. Schematic Presentation of Model 3. Note. ATT = Attitude; MI = Motivational Intensity; DLE = Desire to Learn English; SC = Linguistic Self-Competence; PEC = Perceptions of English Competence; LEA = Lack of English Anxiety; BI = Behavioral Control 
These three models were targeted because of their potential to facilitate understanding about South Korean students' EFL learning from a social psychological perspective. Another reason was that all the theories underlying the three targeted models (i.e., TRA, SM \& Linguistic Self-confidence) have been successfully utilized in the Korean EFL context, except for TPB. Therefore, the full components of TRA and TPB were tested, as noted from Figures 1 and 2. In the case of Gardner's model, however, only the motivation part of the model was tested and the effects of other constructs, such as integrativeness, were not analyzed, mainly because the present study was designed to examine the direct effects of social psychological variables on behavioral intention. In Gardner's model, motivation is the only variable which makes a direct influence on L2 outcomes, whereas the effects of other variables, such as integrative or instrumental orientation, are only indirectly conveyed to L2 outcomes through motivation.

To effectively accomplish the research purposes as stated in the Introduction section of this paper, the following two research questions were formulated.

RQ1: What are the structural relationships between attitude, subjective norm, and behavioral intention for South Korean high school EFL learners?

RQ2: What social psychological model best explains South Korean EFL learners' intention to study English?

\section{Methods}

\subsection{Study Participants}

The study participants were 614 students enrolled at a large metropolitan high school in South Korea. This high school had three grade levels, and all the participants were sampled from grades 1 and 2. The primary purpose of the school was to prepare students for college admissions. Fifty-nine percent of the participants were females, and the age ranged from 14 to 15 . The participants' level of English proficiency was diverse, ranging from a low to a high level, with the majority of students centering around the intermediate level. At the point of the data collection, the mean value of the years of English study in the formal classroom setting was 8.6. In South Korea, English is a compulsory subject from the third grade of elementary school. Data were collected in two steps. First, the researcher contacted the English teachers working at the high school through a teacher education program and explained the purpose of the research. Next, with the permission from the teachers, the researcher visited the local high school classrooms and explained the purpose of the research, this time to the students. The students who signed the research consent form participated in the present research. Data were collected at the individual classroom level, and the entire data collection process took about a week.

\subsection{Instrument}

The present research utilized a survey questionnaire to systematically collect information about the two research questions posed. A questionnaire was developed which elicited South Korean EFL high school students' responses to the targeted variables of the present study. Specifically, the questionnaire consisted of items across five subscales (i.e., attitudes, subjective norm, behavioral control, linguistic self-confidence, and behavioral intention). For item development, previous studies in TRA, TPB, and SM were consulted, and the questionnaire items used in the previous studies were adapted as necessary to make them more sensitive to the South Korean EFL context. All the items were based on a 7-point Likert scale. The questionnaire items were originally written in English and were back-translated into Korean. The Korean version was distributed to the participants. Once the item development was completed, all the items were field-tested to investigate content relevancy and psychometric properties via both qualitative and quantitative item analysis. If an item showed a negative or a very weak power of item discrimination (i.e., item-total correlation value of 0.3 or below), it was removed from subsequent analyses. All the negative items were field-tested in order to present 
the construct in a positive way. Information of the measurement scales used in the present study can be found at Supplementary Materials.

Attitudes towards learning English. Consistent with the definition of attitudes as described by Ajzen and Fishbein [8], six items were developed to measure South Korean students' attitudes towards learning English. To check the validity of this sub-sale, exploratory factor analysis (EFA) was performed using the Eigenvalue 1 or above and a scree plot criterion to determine a factor. Based on the results of EFA, items showing a primary factor loading value below 0.5 and those items with cross-loadings of 0.3 or above were removed from the sub-sale, as per recommendations from previous L2 studies [36,37]. This procedure resulted in an item pool of five items. An additional item analysis of this item pool detected an item showing a lower value of item-total correlation, and this item was also removed. Through this procedure, four items were identified and served as indicator variables for the construct of attitude. Reliability evidence as measured by Cronbach's alpha was 0.93 .

Subjective norm. Six items were adapted from previous social psychological studies, three from Ajzen and Fishbein [8] and three from Cheng, Lam, and Hsu [38], and these items were adapted for the present study context. Following the same item selection procedure described above, four items were finally chosen for the subjective norm subscale. These four items were used as indicator variables for the subjective norm subscale. Cronbach's alpha was 0.90 for the four items.

Perceived behavioral control. This factor measures how competently a person can execute the study of English under specific situations. Six items were developed in reference to Ajzen [7] and Cheng et al. [38]. EFA factor-analytic procedure and item discrimination analysis removed three items, hence resulting in a final set of three items for the subscale of perceived behavioral control. Cronbach's alpha was 0.87 .

Motivational intensity. Five items were borrowed from Gardner's AMTB (Attitudes and Motivation Test Battery, [39]). Two items showing a low item-total correlation were removed from the subscale. Cronbach's alpha was 0.915 for the three items.

Desire to learn English. As with the case of motivational intensity subscale, five items were utilized from the AMTB. Again, two items showed a very lower value of item-total correlation, and these two items were excluded from the item pool. Cronbach's alpha for the remaining three items was 0.835 .

Linguistic self-confidence. Consistent with the construct definition from Clément et al. [32], linguistic self-confidence was measured by two factors (i.e., perceptions of competence in English and lack of English anxiety). Drawing on previous studies of L2 [11,40], 12 items were initially developed to measure linguistic self-confidence. An EFA procedure supported a two-factor solution for these items, one for the perceived English competence factor and the other for the lack of an anxiety factor. Two of the 12 items were dropped because of cross-loadings. An additional item, however, had a much lower value of item discrimination and was hence removed, thereby producing a final set of nine. Two factor scores were extracted according to the two-factor solution, and these two factor scores served as indicator variables for the linguistic self-confidence construct. Cronbach's alpha for the self-competence factor and anxiety factor was 0.87 and 0.91 , respectively.

Behavioral intention. Initially, five items were developed to assess South Korean high school students' intention to learn English based on previous studies $[8,38]$. The results of the EFA procedure supported a one-factor solution for this subscale. Again, two items were flagged as showing a very lower value of item discrimination, and these two items were excluded from the item pool. Cronbach's alpha of the final three items was 0.86 .

\subsection{Data Analysis}

The structural relationships between attitude, subjective norm, and behavioral intention in terms of the South Korean EFL learning context (RQ1) were analyzed using an SEM approach. SEM is a multivariate data analytic technique which enables researchers to simultaneously examine the causal relationships between sets of unobserved or latent variables, which are in turn measured through 
corresponding observed or indicator variables [41]. The overall fit of the proposed SEM model to the sample data is evaluated by chi-square statistics relative to its degrees of freedom. Since chi-square statistics, however, tends to be inflated in a large ample size (i.e., Type I Error), it is often complemented by sets of auxiliary fit indices, such as GFI (Goodness of Fit Index), NNFI (Non-Normed Fit Index), CFI (Comparative Fit Index), and RMSEA (Root Mean Square Error of Approximation), as explained by $\mathrm{Hu}$ and Bentler [42] and Bentler and Bonett [43]. Data of the present study were analyzed using the IBM SPSS AMOS 23 Program. All the parameters in the SEM analysis were calibrated via the maximum likelihood (ML) estimation procedure using a covariance matrix.

The predictive power of these three competing SEM models (RQ2) was empirically compared in terms of three evaluative criteria, following the suggestions of previous studies [41,44]: (1) Model-data fit indices, (2) path coefficients, and (3) $R^{2}$ (variance explained) of the models. Specifically, the three competing models were first evaluated in terms of model-data fit indices. If a model showed an unacceptable fit, which implies that the model fails to adequately represent the sample data, this model was considered disqualified. If competing models showed an equally acceptable level of model-data fit, then these models were evaluated in terms of the strength of path coefficients and their respective predictive power (i.e., $R^{2}$ ). If there were no meaningful differences between the competing models in terms of these two criteria, then the most parsimonious model with fewer parameters was considered the best.

\section{Results}

\subsection{Assessment of Measurement Model}

The measurement model of the latent variables targeted in the present study was assessed by confirmatory factor analysis (CFA). CFA pertains to the measurement part of a full SEM model, and the CFA model in the present study consisted of all the seven latent variables (i.e., attitude, subjective norm, perceived behavioral control, motivational intensity, desire to learn English, linguistic self-competence, and behavioral intention) without specifying the structural relationships between the latent variables. This CFA model produced a chi-square value of 706.87 with 91 degrees of freedom $(p<0.01)$, and the model-data fit indices were satisfactory (e.g., GFI $=0.94, \mathrm{CFI}=0.99, \mathrm{NNFI}=0.98$, RMSEA $=0.066$, SRMR $=0.048$ ). As presented in Table 1 , all the standardized factor loadings between a latent variable and its corresponding indicator variables were significant, ranging from 0.72 to 0.95 , hence suggesting that all the indicator variables were sufficiently powerful in their representation of the corresponding latent variables [45]. Furthermore, evidence of convergent validity of the CFA model was assessed through average variance extracted (AVE) and composite construct reliability (CCR). Convergent validity refers to the degree to which measures of constructs that theoretically should be related are in fact related. An AVE value of 0.5 or above and a CCR value of 0.7 generally indicate an acceptable evidence of convergent validity [46]. As shown in Table 1, all the AVEs and CCRs satisfied the recommended cutoffs, which indicated a strong bonding between the latent variables and their corresponding indicator variables in the CFA model. Discriminant validity, which evaluates the degree to which constructs with dissimilar theoretical orientations differ from each other, was also examined by comparing the AVE values with squared correlation coefficients between latent variables. It was found that all the AVE values were greater than the squared correlation coefficients with values ranging from 0.58 to 0.78 (see Table 2), thereby lending support to the discriminant validity [47]. Taken together, these findings validate the psychometric properties of the measures utilized in the present study. 
Table 1. Assessments of the Measurement Model.

\begin{tabular}{|c|c|c|c|}
\hline Constructs/Indicators & Standardized Factor Loadings & AVE & CCR \\
\hline ATT & & 0.68 & 0.89 \\
\hline ATT1 & 0.88 & & \\
\hline ATT2 & 0.74 & & \\
\hline ATT3 & 0.76 & & \\
\hline ATT4 & 0.91 & & \\
\hline SN & & 0.75 & 0.92 \\
\hline SN1 & 0.79 & & \\
\hline SN2 & 0.88 & & \\
\hline SN3 & 0.95 & & \\
\hline SN4 & 0.83 & & \\
\hline PBC & & 0.78 & 0.91 \\
\hline PBC1 & 0.79 & & \\
\hline PBC2 & 0.93 & & \\
\hline $\mathrm{PBC} 3$ & 0.93 & & \\
\hline MI & & 0.77 & 0.91 \\
\hline MI1 & 0.89 & & \\
\hline MI2 & 0.87 & & \\
\hline MI3 & 0.84 & & \\
\hline DLE & & 0.73 & 0.89 \\
\hline DLE1 & 0.79 & & \\
\hline DLE2 & 0.82 & & \\
\hline DLE3 & 0.73 & & \\
\hline SC & & 0.58 & 0.74 \\
\hline PEC & 0.81 & & \\
\hline LEA & 0.72 & & \\
\hline BI & & 0.76 & 0.91 \\
\hline BI1 & 0.86 & & \\
\hline BI2 & 0.86 & & \\
\hline BI3 & 0.90 & & \\
\hline
\end{tabular}

Note. $\mathrm{N}=614 ; \overline{\mathrm{ATT}}=$ Attitude; $\mathrm{SN}=$ Subjective Norm; $\mathrm{PBC}=$ Perceived Behavioral Control; $\mathrm{MI}=$ Motivational Intensity; DLE= Desire to Learn English; SC = Linguistic Self-Competence; $\mathrm{PEC}=$ Perceptions of English Competence; LEA = Lack of English Anxiety; BI = Behavioral Control; AVE = Average Variance Extracted; CCR = Composite Construct Reliability.

Table 2. Test of Discriminant Validity.

\begin{tabular}{cccccccc}
\hline Factors & $\mathbf{1}$ & $\mathbf{2}$ & $\mathbf{3}$ & $\mathbf{4}$ & $\mathbf{5}$ & $\mathbf{6}$ & $\mathbf{7}$ \\
\hline ATT & $\mathbf{0 . 6 8}$ & 0.065 & 0.278 & 0.284 & 0.227 & 0.332 & 0.329 \\
SN & & $\mathbf{0 . 7 5}$ & 0.075 & 0.008 & 0.056 & 0.056 & 0.183 \\
PBC & & & $\mathbf{0 . 7 8}$ & 0.136 & 0.191 & 0.245 & 0.284 \\
MI & & & & $\mathbf{0 . 7 7}$ & 0.399 & 0.309 & 0.397 \\
DLE & & & & & $\mathbf{0 . 7 3}$ & 0.213 & 0.354 \\
SC & & & & & & $\mathbf{0 . 5 8}$ & 0.206 \\
BI & & & & & & & $\mathbf{0 . 7 6}$
\end{tabular}

Note. The squared values of the correlations between factors are presented in the upper off-diagonal. AVEs are presented in boldface type along the diagonal.

\subsection{Results of Research Question 1}

Research question 1 tested the utility of the social psychological model as represented by TRA. Table 3 presents the SEM analysis results of the triadic relationships between attitude, subjective norm, and behavioral intention (i.e., RQ1). The TRA model resulted in a chi-square value of 91.19 with 37 degrees of freedom $\left(\chi^{2} / d f=2.46\right)$. The fit of the model to the data was deemed satisfactory, as indicated by several acceptable model-data fit indices (e.g., GFI $=0.97, \mathrm{CFI}=0.99, \mathrm{NFI}=0.99$, $\mathrm{NNFI}=0.99, \mathrm{SRMR}=0.04, \mathrm{RMSEA}=0.057$ ). All the factor loadings were significantly strong, ranging from 0.79 to 0.95 , and this evidenced the sufficient power of the indicator variables in representing 
their corresponding latent variables. All the path coefficients among latent variables (i.e., structural model) were also significant. Specifically, a significant direct relationship was found between attitude and behavioral intention, as indicated by a strong path coefficient $(\gamma=0.62)$. This suggests that South Korean EFL high school students with a more positive attitude toward English learning are expected to display a significantly higher level of behavioral intention to study English. In a similar vein, subjective norm was also directly related to behavioral intention, as noted by a significant path coefficient (i.e., $\gamma=0.35$ ). This shows that South Korean high school students' perceptions about the opinions of their significant others regarding English studies significantly impact the degree of their intention to learn English, thereby suggesting that South Korean high school students whose significant others endorse the importance of English learning will have a significantly higher level of intention to study English. Overall, although attitude and subjective norm made an independent contribution to behavioral intention, attitude had a much stronger influence on South Korean high school students' intention to learn English than subjective norm did, as indicated by the substantial difference in the gamma values (i.e., $\gamma=0.62$ vs. $\gamma=0.35$ ), although the difference between the two gamma values was not statistically tested.

\subsection{Results of Research Question 2}

The results of the model comparison for identifying the best social psychological model in the context of South Korean EFL learning (i.e., RQ2) are summarized in Table 3. The utility of the three competing social psychological models (i.e., Models 1-3) was gauged in terms of overall model-data fit indices, the strength of path coefficients, and the proportion of variance explained (i.e., $R^{2}$ ).

Table 3. Overall Fit Indices and Predictive Power of Competing Models.

\begin{tabular}{cccc}
\hline & Model 1 & Model 2 & Model 3 \\
\hline Composition & TRA & TPB & SM Expanded \\
Latent Variables & ATT, SN, BI & ATT, SN, PBC, BI & ATT, MI, DLE, SC, BI \\
\hline \multicolumn{4}{c}{ Fit Indices (Recommended Values) } \\
\hline$\chi^{2} / d f(\leq 3.0)$ & $91.19 / 37=2.46$ & $161.28 / 67=2.41$ & $183.84 / 76=2.42$ \\
GFI $(\geq 0.90)$ & 0.97 & 0.95 & 0.95 \\
CFI $(\geq 0.90)$ & 0.99 & 0.99 & 0.98 \\
NFI $(\geq 0.90)$ & 0.99 & 0.98 & 0.98 \\
NNFI $(\geq 0.90)$ & 0.99 & 0.98 & 0.98 \\
SRMR $(\leq 1.0)$ & 0.040 & 0.039 & 0.039 \\
RMSEA $(\leq 1.0)$ & 0.057 & 0.062 & 0.062 \\
\hline & Structural Relations & $0.38^{*}$ \\
\hline ATT-BI & $0.62 *$ & $0.50 *$ & - \\
SN-BI & $0.35 *$ & $0.25 *$ & - \\
PBC-BI & - & $0.28 *$ & $0.56^{*}$ \\
MI-BI & - & - & $0.17^{*}$ \\
DLE-BI & - & - & $0.21^{*}$ \\
SC-BI & - & & 0.471 \\
Variance Explained & & 0.468 & 0.465 \\
$R^{2}$ & 0.418 & 0.465 & \\
Adjusted $R^{2}$ & 0.416 &
\end{tabular}

Note. See Table $1 .{ }^{*}$ means a significant path coefficient at the alpha level of 0.05 .

As shown in Table 3, all the three competing social psychological models showed an equally acceptable fit of the model to the data, satisfying the recommended values of the fit indices. This indicates that the three social psychological models can be successfully applied to the South Korean EFL context. In terms of standardized path coefficients, all the path coefficients in the TRA, $\mathrm{TPB}$, and the SM Expanded model were statistically significant, ranging from 0.17 to 0.62 . 
With regard to explanatory power as measured by $R^{2}$, the proportion of variance explained by the TPB model (0.468) was much greater than that by the TRA model (0.418), indicating that the TPB model explained more of the variances associated with South Korean EFL learners' intention to study English than the TRA model did. Regarding the comparison between the TPB and SM Expanded model, the SM Expanded showed a higher value of $R^{2}(0.471$ vs. 0.468$)$, and this result reflects the difference in the number of predictor variables between the two models, since $R^{2}$ is sensitive to the number of parameters in the model. However, in terms of adjusted $R^{2}$, which considers the number of parameters in the calculation of the proportion explained, there was no difference between TPB and SM Expanded (0.465 vs. 0.465), and the TPB model showed a substantially higher value of adjusted $R^{2}$ than the TRA model did (0.465 vs. 0.416). Overall, the results of model comparison in terms of fit indices, strength of standardized path coefficients, and proportion of variance explained demonstrate that the TPB model (Model 2) and the SM Expanded model (Model 3) were equally efficient social psychological models of L2 acquisition in the context of South Korean EFL learning.

\section{Discussion}

The results of the present study are discussed in terms of the research findings reported from previous studies and the relationships between social psychological theories and EFL learning in South Korea. The first research question was formulated to test whether the key variables of social psychological theory (i.e., attitude and subjective norm) can account for a significant proportion of the variances in South Korean high school students' intention to learn English. The results show that both South Korean students' attitude toward learning English and their perceptions of significant other's opinions (i.e., subjective norms) made a significant and independent contribution to their intention to learn English, which suggests that South Korean high school students with a more positive attitude and with greater endorsement of their significant other's opinions are more likely to have a higher degree of intention to learn English than their counterparts with a less positive attitude and less strong subjective norm. This finding suggests that the TRA model can be successfully applied to the South Korean EFL learning context, hence being consistent with previous L2 studies which utilized TRA as the theoretical basis [26]. The present study's results also complement the findings reported from Pae [27], which showed that South Korean high school students' attitude toward English and subjective norm significantly impact their EFL achievement as measured by a standardized national English achievement test, hence providing empirical evidence that TRA can work as a theoretical model for predicting different measures of students' learning outcome. This further suggests that English learning in South Korea now has more of the characteristics of social psychological behavior, which is jointly shaped by the learners and the social milieu where the learners are exposed. The present finding, together with other findings of previous TRA studies, also implies that attitudes and subjective norms work as a determinant of diverse social behaviors across different domains, such as communication, consumer and occupation behaviors, tourism, voting, hospitality, and L2 learning [8,38].

The relative magnitude of the effects of attitude and subjective norm on intention also warrants attention. Given the finding that attitude exerted a greater effect on intention than subjective norm did and that this pattern was consistently observed in the TPB model utilized in the present study, as shown in Table 3, it is inferred that learners' attitudes toward a target behavior are more important than the perceived opinions of significant others in forming learners' intention to the targeted behavior. This line of inference further suggests that in order to have a stronger intention to learn an L2, learners should first be armed with a more positive attitude toward L2 learning, with the perceived opinions of significant others boosting and forging the initial attitude. The finding that attitude exerted a greater impact on social behavior than subjective norm did makes logical sense, considering that a person's intention toward a behavior is more influenced by the feelings of the person himself or herself, rather than the perceived feelings of others per se. The superior power of attitude in forming intention is consistent with the findings reported from a study utilizing a Chinese sample [26], 
thus empirically verifying the importance of positive attitudes in L2 learning across different national samples. The present study's finding is also in line with those findings reported from other social psychological studies $[48,49]$, which enhances the generalizability of the present finding.

The results of the model comparison (i.e., RQ2) demonstrate that all the three competing models satisfied the recommended values of the fit indices, hence signaling that all of the three models adequately represent the sample data. In terms of explanatory power as measured by $R^{2}$, which is basically a function of the number of predictor variables in the model, the SM Expanded model (Model 3) showed the highest value of $R^{2}(0.471)$, followed by the TPB (0.468) and TRA models (0.418), and this result is reflective of the fact that the SM Expanded model had more predictor variables than the TPB and TRA models had. As for an adjusted $R^{2}$ value, which adjusts the original $R^{2}$ according to the number of predictors in the model, the TPB model showed a higher value of adjusted $R^{2}$ value than the TRA model did, but there was no difference between the TPB and SM Expanded models. These findings verify that both the TPB and SM Expanded model were equally efficient in predicting South Korean EFL high school students' behavioral intentions to learn English. On the one hand, the result that both the motivation construct as specified by Gardner's SM (i.e., attitudes to toward learning English, motivational intensity, and desire to learn English) and linguistic self-confidence made a significant and independent influence on students' intention is consistent with previous studies with a South Korean sample [11]. This finding further indicates that South Korean high school students with more positive attitudes toward learning English, stronger motivational intensity and desire to learn English, and more self-confidence would lead to a stronger intention to learn English. In terms of the strength of path coefficients, however, the results of the present study show that motivational intensity exerted much more influence on students' intention to learn English $(\gamma=0.56)$ than attitudes $(\gamma=0.38)$, desires $(\gamma=0.17)$, or self-confidence $(\gamma=0.21)$ did. This indicates that cognitive variables, such as motivational intensity, play a more important role in forging learners' intention to study than affective variables do, in line with previous studies [31]. Therefore, the present findings lend empirical support to the validity of the theoretical conceptualization of Gardner's SM, where motivation is specified as a construct making a direct effect on L2 learning outcomes, whereas affective variables are assumed to have an indirect effect on L2 learning outcomes through motivation. The observation that the SM Expanded model adequately works in the South Korean EFL context as a theory for explaining South Korean students' EFL learning complements the results of RQ1, and it further suggests that a social psychological model of L2 acquisition may function more efficiently if there is a cognitive element in it. It also deserves attention that the results of RQ2 broaden the scope of the theories proposed by Gardner and Clément by integrating an empirical finding about the relationships between motivation, self-confidence, and L2 learning intentions to the existing database on these theories, since the effects of motivation and self-confidence on L2 learning intentions have not received sufficient empirical attention from $\mathrm{L} 2$ researchers.

On the other hand, the finding that the TPB model can be successfully applied to the South Korean EFL context also warrants discussion. This means that learners' perceptions of their ability to perform the behavior in question (i.e., perceived behavioral control) also function as a significant booster in empowering their intention to study English in addition to their attitude and subjective norm. This finding is consistent with previous L2 studies, which used TPB as a theoretical base for modeling various aspects of L2 acquisition, such as intentional behavior, WTC, or L2 curriculum impact $[29,30]$. Taken together, findings of the present study demonstrate that adding a nonvolitional factor of perceived behavioral control to the TRA model substantially enhances the predictive power of a social psychological model of L2 learning. However, the present study findings need to be replicated in future research with different samples because this is the first study to systematically examine the effects of perceived behavioral control in relation to L2 learning in the South Korean EFL setting. 


\section{Conclusions}

Social psychological theories have rarely been utilized to examine South Korean learners' EFL learning, although EFL learning in South Korea is now not only a matter of academic activity based on cognitive functioning but also a social behavior co-constructed by the learner and the environment. In this regard, social psychological theories of L2 acquisition have the potential for sustainable EFL learning and teaching in Korea. The results of the present study indicate that South Korean high school students' attitudes toward learning English and the perceptions of their significant others' opinions in reference to English learning made a significant and independent contribution to the variance in students' intention to study English, hence verifying that the two key variables in TRA also work in the context of South Korean EFL learning. Among the three competing social psychological models compared in the current study, the TPB model and the SM Expanded Model proved to be the most powerful in terms of the strength of path coefficients and explanatory power.

\subsection{Theoretical and Pedagogical Implications}

The findings of the present study hold both theoretical and pedagogical implications for EFL learning in South Korea. On the theoretical side, these results suggest that attitude, subjective norm, and perceived behavioral control along with traditional Gardnerian social psychological variables (e.g., desire to learn English) provide very efficient theoretical tools to probe factors affecting South Korean students' EFL learning, thus complementing the research database on Gardner's or Clément's theory of L2 achievement. This implies that English learning in South Korea is more than an academic school subject, which has traditionally been studied in terms of individual differences variables, such as learner differences in linguistic ability [12,50]. Rather, the present study results demonstrate that South Korean high school students' EFL learning can be better examined through a social psychological lens, which views diverse social behaviors as a co-constructed output resulting from interactions between the learner and various social environmental variables. Therefore, it is reasonable to believe that social psychological variables, such as subjective norm and perceived behavioral control, can cast a light on the complex process of L2 learning, particularly in the context of South Korean EFL learning. It should be noted, however, that social psychological variables, such as subjective norm or perceived behavioral control, are not the only pathway to look into the complex mechanism of L2 achievement in the South Korean EFL context, since the variables specified in the SM Expanded model were also found to be equally powerful in explaining South Korean EFL learners' intentions to study English. In this regard, the conceptual similarities between the TPB and SM Expanded model deserve further attention. First of all, both models share attitudes as a common element. In addition, the perceived behavioral control in the TPB model is conceptually similar to the self-confidence factor in the SM Expanded model in that the two factors commonly touch upon learners' self-perceptions of their ability. These similarities between the TPB and SM Expanded models may partially explain the results of RQ2, where both of the two models were found to be equally effective.

On the pedagogical side, the present study findings highlight the importance of the influences from significant others, such as teachers or family members, in shaping and strengthening EFL learners' intentional behaviors. Accordingly, it is critical that teachers or family members do their best to motivate students to have a better attitude towards targeted EFL learning behaviors. For instance, classroom teachers can help learners to develop a more positive attitude toward EFL learning through innovative teaching methods and authentic teaching materials which attract learners' attention and promote their intrinsic motivation. Given the finding that learners' perceived competence in executing a targeted behavior (i.e., perceived behavioral control) and linguistic self-confidence significantly enhance South Korean high school students' English learning intention, it is recommended that EFL teachers do not scare off their students. In this respect, students' participation should be maximized in selecting and organizing course materials or in determining assessment policy, thus enhancing students' autonomy, which certainly gives learners a feeling of "I can do". 
Considering the study finding that motivational intensity proved to be the strongest factor affecting South Korean high school students' intentions to learn English, it is also desirable that EFL teachers find a way to motivate their students to make more efforts to L2 study. Since previous studies indicate that a sense of achievement or a positive attitude helps learners to expend a higher degree of efforts [40,51], teachers are advised to make sure that their students experience small successes through less challenging measures of assessment. This way, students are encouraged to experience more senses of achievement or more positive perceptions about their competence, and these enhanced feelings about themselves in turn will lead them to learn more.

Three study limitations warrant mention. First, this study was based on a highly homogeneous sample of South Korean EFL learners enrolled in a local high school and, therefore, the findings should be replicated in further research with samples of diverse age ranges (e.g., middle school or university students) and different characteristics. Second, the response data collected may have been vulnerable to a social bias, in that respondents might have given a socially appropriate answer to some of the questionnaire items to save the respondents' or their teachers' face, as is the case with most of the studies with a questionnaire survey design. In this regard, a research design which directly investigates the combined effects of attitude, subjective norm, and perceived behavioral control on an objective measure of learning outcome (e.g., course achievement) was deemed preferable. Such as design, however, was not feasible in the present study, since an SEM model implementing such a design did not converge and therefore the effects were not to be gauged. Finally, the current results are only generalizable to those EFL countries with a cultural or sociological orientation similar to South Korea. Similarly, it is notable that the present study was conducted in South Korea where English is a compulsory school subject and competence in English is a high-stakes asset. Therefore, caution is advised in generalizing the study findings to other countries with different cultural and educational contexts.

\subsection{Impications for Sustainable L2 Learning}

Given the importance of $\mathrm{L} 2$ as a powerful tool for understanding people and society with culturally different orientations, the sustainability of L2 learning cannot be overemphasized. Then, how can L2 learning be a sustainable project? In this regard, the psychology of sustainability and sustainable development provides a useful direction for promoting a sustainable L2 learning. According to Di Fabio, the sustainability of a project depends on the identification of "the zone of proximal sustainable development" ([52], p. 3), where sustainable development is accomplished by a macrolevel approach to the relationship between people and society. The present study exemplifies a successful application of the psychology of sustainability and sustainable development to the investigation of the factors influencing sustainable EFL learning in Korea. Specifically, the present study focused on behavioral intention to learn English as a variable conducive to sustainable EFL learning and, as consistent with the principles of psychology of sustainability and sustainable development $[4,52,53]$, we analyzed the macrolevel relationships between social psychological variables and people's intention to learn English. The study results demonstrate that social psychological variables, such as positive attitudes, social norms, behavioral control, and motivations, made a significant impact on Korean learners' intention to study English, further indicating that the psychology of sustainability and sustainable development helps to enhance the life quality of people through sustainable L2 learning [52]. Future research efforts should be directed at the examinations of other factors that directly or indirectly contribute to fostering the sustainability of L2 learning.

Supplementary Materials: The following are available online at http:/ /www.mdpi.com/2071-1050/11/1/16/s1, Table S1: Summary of Measurement Scales title.

Author Contributions: Conceptualization, K.K.; Formal analysis, T.P.; Funding acquisition, K.K.; Methodology, T.P.; Writing—original draft, T.P.; Writing—review and editing, K.K. 
Funding: This study was supported by research fund from Chosun University, 2018.

Conflicts of Interest: The authors declare no conflict of interest.

\section{References}

1. United Nations. Sustainable Development Goals: 17 Goals to Transform Our World. 2015. Available online: http:/ / www.un.org/sustainabledevelopment/development-agenda/ (accessed on 30 November 2018).

2. Zygmunt, T. Language education for sustainable development. Discourse Commun. Sustain. Educ. 2016, 7, 112-124. [CrossRef]

3. Di Fabio, A.; Kenny, M.E. Connectedness to nature, personality traits and empathy from a sustainability perspective. Curr. Psychol. 2018. [CrossRef]

4. Di Fabio, A.; Rosen, M.A. Opening the black box of psychological processes in the science of sustainable development: A new frontier. Eur. J. Sustain. Dev. Res. 2018, 2, 47. [CrossRef]

5. UNESCO Bangkok. Definition of ESD. Available online: http://www.unescobkk.org/education/esd-unit/ definition-of-esd/ (accessed on 30 November 2018).

6. Fishbein, M.; Ajzen, I. Belief, Attitude, Intention, and Behavior: An Introduction to Theory and Research; Addison-Wesley: Reading, MA, USA, 1975.

7. Ajzen, I. From intentions to actions: A theory of planned behavior. In Action Control: From Cognition to Behavior; Kuhl, J., Beskmann, J., Eds.; Springer: New York, NY, USA, 1985.

8. Ajzen, I.; Fishbein, M. Understanding Attitude and Predicting Social Behavior; Prentice Hall: Englewood Cliffs, NJ, USA, 1980.

9. Dörnyei, Z. Motivation in second and foreign language learning. Lang. Teach. 1998, 31, 117-135. [CrossRef]

10. Gardner, R.C. Integrative motivation and second language acquisition. In Motivation and Second Language Acquisition; Dörnyei, Z., Schmidt, R., Eds.; University of Hawaii, Second Language Teaching and Curriculum Center: Honolulu, HI, USA, 2001.

11. Pae, T.-I. Second language orientation and self-determination theory: A structural analysis of the factors affecting second language achievement. J. Lang. Soc. Psychol. 2008, 27, 5-27. [CrossRef]

12. Brown, D. Principle of Language Learning and Teaching; Longman: New York, NY, USA, 2007.

13. Nunan, D. Communicative tasks and the language curriculum. TESOL Q. 1991, 25, 279-295. [CrossRef]

14. Kwon, O. Korea's English education policy changes in the 1990s: Innovations to gear the nation for the 21st century. Engl. Teach. 2000, 55, 47-91.

15. Park, J.-K. English fever in South Korea: Its history and symptoms. Engl. Today 2009, 25, 50-57. [CrossRef]

16. Kim, K. Reading motivation in two languages: An examination of EFL college students in Korea. Read. Writ. 2011, 24, 861-881. [CrossRef]

17. Kim, K. Motivation and its changes of Korean EFL middle school students. J. Linguist. Sci. 2015, 72, 1-20.

18. Shim, J. A study of foreign language learning motivation in Korean university students. Stud. Br. Am. Lang. Lit. 2011, 99, 287-306.

19. Lee, H. "I am a kirogi mother": Education exodus and life transformation among Korean transnational women. J. Lang. Identity Educ. 2010, 9, 250-264. [CrossRef]

20. Park, K. Korean wild geese families: Global education and transnationalizing as a family strategy for class mobility. Glob. Stud. J. 2012, 5, 67-78. [CrossRef]

21. Onishi, N. For English studies, Koreans say goodbye to dad. New York Times, 8 June 2008; A1.

22. Yang, K.S. Social orientation and individual modernity among Chinese students in Taiwan. J. Soc. Psychol. 1981, 113, 159-170. [CrossRef]

23. Eagly, A.H.; Chaiken, S. Psychology of Attitudes; HBJ: Fort Worth, TX, USA, 1993.

24. Ajzen, I.; Driver, B.E. Applied of the theory of planned behavior to leisure choice. J. Leisure Res. 1992, 24, 207-224. [CrossRef]

25. Ajzen, I. The theory of planned behavior. Organ. Behav. Hum. Decis. Process. 1991, 50, 179-211. [CrossRef]

26. Livesey, D.; Crawley, F.; Blanco, G. An Application of the Theory of Reasoned Action for Reading Attitudes, Social Support and Behavioral Intention in an EFL Setting. Paper Presented at the Annual Meeting of the Teachers of English to Speakers of Other Languages, Vancouver, BC, Canada, 3-7 March 1992. 
27. Pae, T.-I. Examining English achievement model by proficiency level for Korean high school students. Hum. Res. 2015, 75, 249-282.

28. Park, J. Understanding Consumer Intention to Shop Online. Unpublished. Ph.D. Thesis, University of Missouri, Columbia, MO, USA, 2003.

29. Underwood, P.R. Teacher beliefs and intentions regarding the instruction of English grammar under national curriculum reform: A theory of planned behavior perspective. Teach. Teach. Educ. 2012, 28, 911-925. [CrossRef]

30. Zhong, Q. Understanding Chinese learners' willingness to communicate in a New Zealand ESL classroom: A multiple case study drawing on the theory of planned behavior. System 2013, 41, 740-751. [CrossRef]

31. Masgoret, A.-M.; Gardner, R.C. Attitudes, motivation, and second language learning: A meta-analysis of studies conducted by Gardner and associates. Lang. Learn. 2003, 53, 123-163. [CrossRef]

32. Clément, R.; Dörnyei, Z.; Noels, K. Motivation, self-confidence and group cohesion in the foreign language classroom. Lang. Learn. 1994, 44, 417-448. [CrossRef]

33. Clément, R.; Gardner, R.; Smythe, P. Motivational variables in second language acquisition: A study of francophones learning English. Can. J. Behav. Sci. 1972, 9, 123-133. [CrossRef]

34. Clément, R. Ethnicity, contact and communicative competence in a second language. In Language: Social Psychological Perspectives; Giles, H., Robinson, W.P., Smith, P.M., Eds.; Pergamon: Oxford, UK, 1980.

35. Clément, R.; Kruidenier, B.G. Aptitude, attitude and motivation in second language proficiency: A test of Clément's model. J. Lang. Soc. Psychol. 1985, 4, 21-37. [CrossRef]

36. Cheng, Y.; Horwitz, E.; Schallert, D. Language anxiety: Differentiating writing and speaking components. Lang. Learn. 1999, 49, 417-446. [CrossRef]

37. Pae, T.-I. Skill-based L2 anxieties revisited: Their intra-relations and the inter-relations with general foreign language anxiety. Appl. Linguist. 2013, 34, 232-252. [CrossRef]

38. Cheng, S.; Lam, T.; Hsu, C. Negative word-of-mouth communication intention: An application of the theory of planned behavior. J. Hosp. Tour. Res. 2009, 30, 95-116. [CrossRef]

39. Gardner, R.C. The Attitude Motivation Test Battery: Technical Report; University of West Ontario, Department of Psychology: London, ON, Canada, 1985.

40. Noels, K.A. Learning Spanish as a second language: Learners' orientations and perceptions of their teachers' communication style. Lang. Learn. 2001, 51, 107-144. [CrossRef]

41. Hair, J.F.; Anderson, R.E.; Tatham, R.L.; Black, W.C. Multivariate Data Analysis; Prentice Hall: Upper Saddle River, NJ, USA, 1995.

42. Hu, L.; Bentler, P.M. Cut-off criteria for fit indexes in covariance structure analysis: Conventional criteria versus new alternatives. Struct. Equ. Model. 1999, 6, 1-55. [CrossRef]

43. Bentler, P.M.; Bonett, D.G. Significance tests and goodness of fit in the analysis of covariance structures. Psychol. Bull. 1980, 88, 588-606. [CrossRef]

44. Taylor, S.; Todd, P. Understanding information technology usage: A test of competing models. Inf. Syst. Res. 1995, 6, 144-176. [CrossRef]

45. Anderson, J.C.; Gerbing, D.W. Structural equation modeling in practice: A review and recommended two-step approach. Psychol. Bull. 1998, 103, 411-423. [CrossRef]

46. Nunnally, J.; Berstein, H. Psychometric Theory; McGraw Hill: New York, NY, USA, 1994.

47. Fornell, C.; Larcker, D. Evaluating structural equation models with unobservable variables and measurement error. J. Mark. Res. 1981, 18, 39-50. [CrossRef]

48. Armitage, C.; Conner, M. Distinguishing perceptions of control from self-efficacy: Predicting consumption of a low-fat diet using the theory of planned behavior. J. Appl. Soc. Psychol. 1999, 29, 72-90. [CrossRef]

49. Zinini, D.M. Participation Decisions by Local Union Members: The Theory of Planned Behavior and Personality; McMaster University: Hamilton, ON, Canada, 2003.

50. Cook, V.; Singleton, D. Key Topics on Second Language Acquisition; Multi-lingual Maters: New York, NY, USA, 2014.

51. Elkhafaifi, H. Listening comprehension and anxiety in the Arabic language classroom. Mod. Lang. J. 2005, 89, 206-220. [CrossRef] 
52. Di Fabio, A. The psychology of sustainability and sustainable development for well-being in organizations. In Emerging and Re-Emerging Organizational Features, Work Transitions and Occupational Risk Factors: The Good, the Bad, the Right. An Interdisciplinary Perspective; Arcangeli, G., Giorgi, G., Mucci, N., Bernaud, J.-L., Di Fabio, A., Eds. Front. Psychol. Organ. Psychol. 2017, 8, 1534. [CrossRef] [PubMed]

53. Di Fabio, A. The psychology of sustainability and sustainable development for well-being in organizations. In Emerging and Re-Emerging Organizational Features, Work Transitions and Occupational Risk Factors: The Good, the Bad, the Right. An Interdisciplinary Perspective; Arcangeli, G., Giorgi, G., Mucci, N., Bernaud, J.-L., Di Fabio, A., Eds. Front. Psychol. Organ. Psychol. 2017, 8, 1938. [CrossRef]

(C) 2018 by the authors. Licensee MDPI, Basel, Switzerland. This article is an open access article distributed under the terms and conditions of the Creative Commons Attribution (CC BY) license (http:/ / creativecommons.org/licenses/by/4.0/). 